\title{
New online method for water isotope analysis of speleothem fluid inclusions using laser absorption spectroscopy (WS-CRDS)
}

\author{
S. Affolter ${ }^{1,2}$, D. Fleitmann ${ }^{2,3}$, and M. Leuenberger ${ }^{1,2}$ \\ ${ }^{1}$ Climate and Environmental Physics, Physics Institute, University of Bern, 3012 Bern, Switzerland \\ ${ }^{2}$ Oeschger Centre for Climate Change Research, University of Bern, 3012 Bern, Switzerland \\ ${ }^{3}$ now at: Department of Archaeology, School of Archaeology, Geography and Environmental Sciences and Centre for Past \\ Climate Change, University of Reading, Whiteknights, P.O. Box 227, Reading RG6 6AB, UK
}

Correspondence to: S. Affolter (affolter@ climate.unibe.ch)

Received: 26 December 2013 - Published in Clim. Past Discuss.: 28 January 2014

Revised: 4 May 2014 - Accepted: 19 May 2014 - Published: 4 July 2014

\begin{abstract}
A new online method to analyse water isotopes of speleothem fluid inclusions using a wavelength scanned cavity ring down spectroscopy (WS-CRDS) instrument is presented. This novel technique allows us simultaneously to measure hydrogen and oxygen isotopes for a released aliquot of water. To do so, we designed a new simple line that allows the online water extraction and isotope analysis of speleothem samples. The specificity of the method lies in the fact that fluid inclusions release is made on a standard water background, which mainly improves the $\delta D$ robustness.

To saturate the line, a peristaltic pump continuously injects standard water into the line that is permanently heated to $140{ }^{\circ} \mathrm{C}$ and flushed with dry nitrogen gas. This permits instantaneous and complete vaporisation of the standard water, resulting in an artificial water background with well-known $\delta D$ and $\delta^{18} \mathrm{O}$ values. The speleothem sample is placed in a copper tube, attached to the line, and after system stabilisation it is crushed using a simple hydraulic device to liberate speleothem fluid inclusions water. The released water is carried by the nitrogen/standard water gas stream directly to a Picarro L1102-i for isotope determination. To test the accuracy and reproducibility of the line and to measure standard water during speleothem measurements, a syringe injection unit was added to the line.

Peak evaluation is done similarly as in gas chromatography to obtain $\delta D$ and $\delta^{18} \mathrm{O}$ isotopic compositions of measured water aliquots. Precision is better than $1.5 \%$ ofor $\delta D$ and $0.4 \%$ for $\delta^{18} \mathrm{O}$ for water measurements for an extended range ( -210 to $0 \%$ for $\delta D$ and -27 to $0 \%$ ofor $\delta^{18} \mathrm{O}$ ) primarily dependent on the amount of water released from
\end{abstract}

speleothem fluid inclusions and secondarily on the isotopic composition of the sample. The results show that WS-CRDS technology is suitable for speleothem fluid inclusion measurements and gives results that are comparable to the isotope ratio mass spectrometry (IRMS) technique.

\section{Introduction}

Speleothems are being used more and more for paleoclimate reconstructions due to their widespread occurrence and potential to deliver precisely dated and highly resolved climatic records covering very long time intervals (e.g. Cheng et al., 2009; Badertscher et al., 2011). To date, the vast majority of speleothem-based paleoclimate reconstructions are based on oxygen isotope $\left(\delta^{18} \mathrm{O}\right)$ measurements on calcite. However, their interpretation remains difficult as they can be influenced by several and sometimes competing climatic and nonclimatic factors (Lachniet, 2009), such as changes in seasonality of rainfall, varying cave air temperatures and evaporation. Fluid inclusions are common in speleothems $(0.05$ to 0.5 weight \%) and are natural repositories of cave drip water (Scheidegger et al., 2010). Therefore, the hydrogen $(\delta D)$ and oxygen $\left(\delta^{18} \mathrm{O}\right)$ isotopic composition of fluid inclusions contains direct information on the isotopic composition of paleoprecipitation (Dennis, 1997; Baker and Bradley, 2010) and, when combined with isotopic analyses of speleothem calcite, it can be used to calculate either paleotemperatures (McGarry et al., 2004; Tremaine et al., 2011) or to reveal changes in the source of moisture (Fleitmann et al., 2003). However, 
one must keep in mind that speleothem calcite $\delta^{18} \mathrm{O}$ values are often affected by kinetic fractionation (Mickler et al., 2006). It has therefore been suggested to use the empirical isotope temperature fractionation relationship for cave calcite originating from many different caves that already inherently captures the disequilibrium during the calcite precipitation (Tremaine et al., 2011). The effects of kinetic fractionation can be assessed and calculated by comparing calcite and parent drip water isotope $\delta^{18} \mathrm{O}$ values. Another way would be to combine clumped isotopes $(\Delta 47)$ and stable isotopes from fluid inclusions to correct for isotopic disequilibrium (Daeron et al., 2011; Wainer et al., 2011). Moreover, the relationship between $\delta^{18} \mathrm{O}$ in the atmosphere, drip water and fluid inclusions has been described in close detail by Lachniet ( 2009). Though the potential of isotope measurements of fluid inclusion water is now fully recognised, various analytical limitations (e.g. sample size restrictions, time-consuming analysis, fractionation processes during extraction of fluid inclusion water) make a wider application of this crucial climate proxy difficult.

The relationship between cave drip water trapped in fluid inclusions and precipitations was first established by Harmon et al. (1979). Later, it was also shown that cave temperature generally reflects the mean temperature at the surface (Fairchild et al., 2006), so fluid inclusions are consequently a key parameter for reconstructing continental paleotemperatures. More recently, experiments have shown that fluid inclusions in "pool spar" preserve both the oxygen and hydrogen isotopic composition of parent drip water (Dublyansky and Spötl, 2009). It remains to be shown that their findings are also valid for fluid inclusions of stalagmites.

To extract water from speleothem fluid inclusions, two different techniques have been used in the past three decades: (i) the extraction by crushing the sample and (ii) the extraction by thermal decrepitation. Originally, investigation of inclusions in speleothems using the crushing extraction procedure was initiated by pioneering work in the late seventies (Schwarcz et al., 1976; Harmon et al., 1978; Harmon et al., 1979). Dennis et al. (1997) improved the precision for hydrogen isotopes of fluid inclusions using the zinc reduction method and a vacuum crushing device coupled to a cold trap cell. He was the first to introduce a combined oxygen and hydrogen isotope analysis of fluid inclusions (Dennis et al., 2001). Since then considerable advances have been made, in particular, in applying online techniques either for the isotope analyses of calcite (Smalley et al., 1989) or of water released from different archives such as ice cores, speleothems, etc. (Huber and Leuenberger, 2003; Leuenberger and Huber, 2002; Morrison et al., 2001). Analyses of both water isotopes in a unique measurement were achieved using the pyrolysis coupled to the IRMS technique and gas chromatography (Gehre et al., 2004; Sharp et al., 2001). More recently, the same method was adapted and modified to perform successful water isotope analysis of speleothem fluid inclusions (Vonhof et al., 2006; Dublyansky and Spötl, 2009).
The second technique is the use of thermal decrepitation at temperatures of around $550{ }^{\circ} \mathrm{C}$ to extract water (Yonge, 1982). Several studies showed a large fractionation of up to $30 \%$ ofor $\delta D$ in comparison with parent cave drip waters (Yonge, 1982; Matthews et al., 2000; McGarry et al., 2004). No fractionation is observed when the speleothem sample is heated to a maximal temperature of $400^{\circ} \mathrm{C}$ (Verheyden et al., 2008).

Current research focuses on the extraction of fluid inclusion water at low temperatures $\left(\sim 140^{\circ} \mathrm{C}\right)$ with the use of laser spectroscopy as a valuable alternative to the traditional IRMS detection technique (Arienzo et al., 2013). Measurements of water extracted from minerals were also achieved using a laser-based technique (Koehler and Wassenaar, 2012; Hodell et al., 2012). The use of laser spectroscopy is growing rapidly and is now being recognised as a reliable, precise and easy-to-use technique for water isotope analysis as mass spectrometry (Brand et al., 2009), and using it for speleothem fluid inclusion measurement constitutes a logical extension for this technique. Water isotope measurements with laser spectroscopy are nowadays mainly used for continuous atmospheric isotope measurements (Aemisegger et al., 2012) as well as for discrete water measurements (Brand et al., 2009).

We present one of the first applications of the laser absorption technique to measure fluid inclusion water extracted from the speleothem calcite. The particularity of the method is that the line is always kept under humid conditions as a water background is continuously generated. To generate the water background, a procedure similar to the calibration protocol for atmospheric measurement is used (Iannone et al., 2009; Sturm and Knohl, 2010), and it requires the vaporisation of a water standard in a vaporisation system. Compared to the crushing device of the Amsterdam line (Vonhof et al., 2006), our line is used to investigate whether the removal of any cryogenic traps prior to the analysis is an advantage.

This paper discusses the technical aspects of the newly designed line, the calibration of the laser instrument and the evaluation of the data. Furthermore, it documents the accuracy and precision of the method for standard and real sample measurements.

\section{Method}

\subsection{Line description}

The new line consists of basically three units: (i) a water background generator for improved instrumental performance; (ii) a syringe injection unit to allow single injections of small aliquots of standard water and (iii) a simple homemade crushing device. 


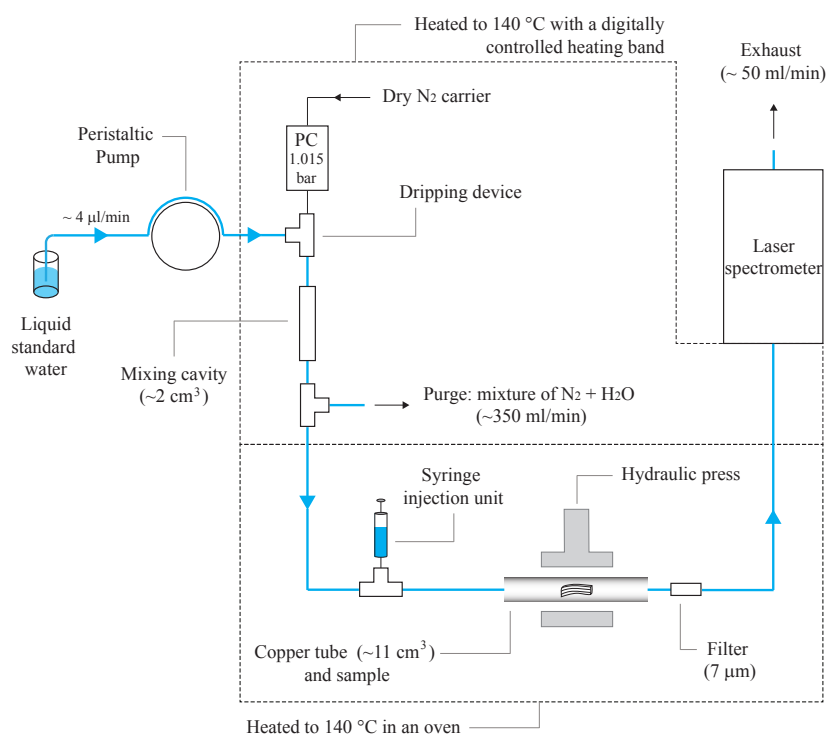

Figure 1. Diagram of the speleothem fluid inclusions water extraction line.

The whole line, shown in Fig. 1, is flushed with nitrogen gas to transfer the water sample from the crushing device to the Picarro L1102-i analyser (Picarro Inc., Sunnyvale, CA, USA). The delivery of nitrogen gas to the line is controlled by an Analyt-MTC pressure regulator (Analyt-MTC GMBH, Müllheim, Germany), which is set to regulate a constant pressure of 1.015 bars over atmosphere. Detailed information of all three units is provided below.

A vaporisation unit (water background generator) was designed to generate a stable water vapour mixing ratio and isotopic background via a constant supply of internal standard water (ST-08) with well-known $\delta D$ and $\delta^{18} \mathrm{O}$ isotopic values into a nitrogen stream using a Union Tee connector as a simple dripping device. Droplets of standard water are supplied by an Ismatec IP High Precision Multichannel Pump (IDEX Health \& Science GmbH, Wertheim, Germany), via a $0.13 \mathrm{~mm}$ inside-diameter TYGON R3607 capillary extended with a heat-resistant $1 / 32^{\prime \prime}$ stainless steel capillary. The peristaltic pump is well suited for continuous injections of standard water at a rate of $\sim 4 \mu \mathrm{min}^{-1}$ (depending on the capillary diameter and the pump speed) into the dripping device. Performance of the pump was tested by monitoring the supply of standard water for $20 \mathrm{hr}$ at intervals of $1 \mathrm{~s}$ using a Sensirion Mass Flow Controller (Sensirion AG, Staefa, Switzerland) that was placed right after the pump. This test showed that the average delivered amount of water is $4.8 \pm 1 \mu \mathrm{min}^{-1}$, whereas short-term fluctuations (over $5 \mathrm{~s})$ range between 2.72 and $7.38 \mu \mathrm{min}^{-1}$. However, these are smoothed out by the mixing volume, the crusher device as well as the whole line. The dripping device is an integral part of the water background generator where dry nitrogen and standard water are injected into the line via a capillary that slightly touches the wall of the stainless steel line (con- necting lines are all made with Swagelok $1 / 8^{\prime \prime}$ stainless steel tubes). The advantages of this design are that the droplets are vaporised instantaneously and formation of large bubbles at the tip of the capillary is minimised to prevent a delay in the release of water. The temperature $\left(140^{\circ} \mathrm{C}\right)$ and the pressure are kept constant inside the line to ensure total and instantaneous vaporisation of the water without isotopic fractionation. The vaporised water is carried along the line by nitrogen gas. The pump speed can be adjusted in a range of water vapour mixing ratio ranging from $\sim 6700 \mathrm{ppmv}$ to the detection limit of the laser spectrometer (including the purge unit). The nitrogen pressure has been selected such that the stability of the water background is enhanced. The water vapour and dry nitrogen are mixed homogeneously in the mixing cavity, which has a volume of $\sim 2 \mathrm{~cm}^{3}$ and is placed immediately after the injection unit, in order to minimise fluctuations caused by the peristaltic pump and to improve the stability of the water background.

As the injected water vapour mixing ratio would be too high for the sensitivity of the Picarro, a $10 \mathrm{~cm}$ stainless steel capillary purge has been added after the mixing cavity, which releases a $\sim 350 \mathrm{ml} \mathrm{min}^{-1}$ dry nitrogen/water vapour mixture. The remaining fraction $\left(65 \pm 0.1 \mathrm{ml} \mathrm{min}^{-1}\right)$ passes through the line and yields a stable isotopic background for $\delta D$ and $\delta^{18} \mathrm{O}$ (see Sect. 2.4 for further details). Moreover, this setup allows us to maintain a quite stable water vapour mixing ratio over time.

A syringe injection unit has been placed prior to the crushing unit to perform reproducibility tests using various standard waters and to make calibration peaks during speleothem fluid inclusion measurements. It is made of a customised Union Tee connector with an added 7/16" Marathon septum to seal it and a piece to drive a needle inside the line. The septum should be replaced regularly as variations of pressure can lead to a loss of stability when the septum is deteriorated. Liquid water samples ranging from 1 to $2 \mu \mathrm{l}$ were injected using a $10 \mu \mathrm{l}$ Hamilton syringe, whereas for lower amounts we used a $1 \mu \mathrm{l}$ SGE Analytical Science syringe.

The crushing device has a simple design and consists of a Power Team P12 hydraulic press (Power Team, Rockford, IL, USA) that exerts a pressure of 220 bars onto the copper tube, which corresponds to a force of approximately 10000 Newton. A $7 \mu \mathrm{m}$ Swagelock inline filter was placed after the copper tube to prevent calcite particles travelling to the laser spectrometer, which may damage the laser instrument. Crushing of the sample generates no leaks or cracks in the copper tube. To estimate the crushing efficiency, a grain size analysis has been made on one sample that led to the following size distribution: $20 \%$ for the fraction 0 $<x<0.149 \mathrm{~mm}, 30 \%$ for $0.149<x<0.495$ and $50 \%$ for $x>0.495 \mathrm{~mm}$, with possible individual particles of up to $1 \mathrm{~mm}$ in size.

After syringe injection or sample crushing, the released water is mixed with the nitrogen/standard vapour mixture to 
form a three-component gas that is then flushed to the laser spectrometer through a stainless steel capillary.

The entire line is uniformly heated to $140^{\circ} \mathrm{C}$ by two heating sources without any cold spots to vaporise a very large quantity of water completely and to avoid condensation and accumulation of water in dead volumes. Compared to a line at room temperature, a heated line minimises the water adsorption on its wall. As shown in Fig. 1, the vaporisation unit, including the water pump inlet, the mixing cavity and the purge, are heated to $140^{\circ} \mathrm{C}$ using a digitally controlled heating band that allows a precise temperature control over time. The injection unit and the speleothem crushing unit are placed in an oven where the temperature is also kept at $140^{\circ} \mathrm{C}$.

Once the three-component (nitrogen/standard water/sample water) mixture reaches the laser spectrometer, it passes through the vaporiser chamber, which is equally heated to $140{ }^{\circ} \mathrm{C}$, into the optical cavity cell where it is measured at precisely controlled pressure and temperature conditions of 35 Torr and $80^{\circ} \mathrm{C}$, respectively. The WS-CRDS operation procedure is well established and further details are described in Crosson (2008) and Gupta et al. (2009).

Results are given in parts per million by volume (ppmv) for the water vapour mixing ratio and in permil $(\% o)$ for the isotopic compositions. They are normalised and expressed against the common Vienna Standard Mean Ocean Water (VSMOW) standard.

\subsection{Sample preparation}

Firstly, a parallelepiped of calcite with a width of $25 \mathrm{~mm}$, a height of $5 \mathrm{~mm}$ and a variable length taken along the growth axis of the stalagmite is extracted (preferably with apex in the middle). This piece of calcite is then cut into $50 \mathrm{~mm}$ long pieces and fixed with glue on both sides of a glass thin section to avoid disintegration of the sample during the cutting process (Fig. 2). This also allows one to follow a marker layer by using a commercially available 3032 Precision Horizontal Diamond Wire Saw (Well Diamond Wire Saw SA, Le Locle, Switzerland) equipped with a $0.3 \mathrm{~mm}$ wire. This setup allows one to cut the sample without any significant loss of material and, moreover, to cut the calcite by making curves by manually adjusting a mechanical screw.

In addition, a $200 \mu \mathrm{m}$ thin section to evaluate the distribution and volume of the fluid inclusions is prepared. One of the advantages of such a preparation is that once the abundance of fluid inclusions is accessed, the thickness of the sample can be adjusted. After the samples are cut, they are placed in a bath of acetone for a couple of hours to remove the residual glue that may have remained on the sample.

The sample varying between 0.1 and $1 \mathrm{~g}$ is then placed in a $\sim 16 \mathrm{~cm}$ long high-purity copper tube with a diameter of $3 / 8^{\prime \prime}$ inch, which has been prepared and cleaned with acetone and flushed with dry air to remove any residual dust. The copper

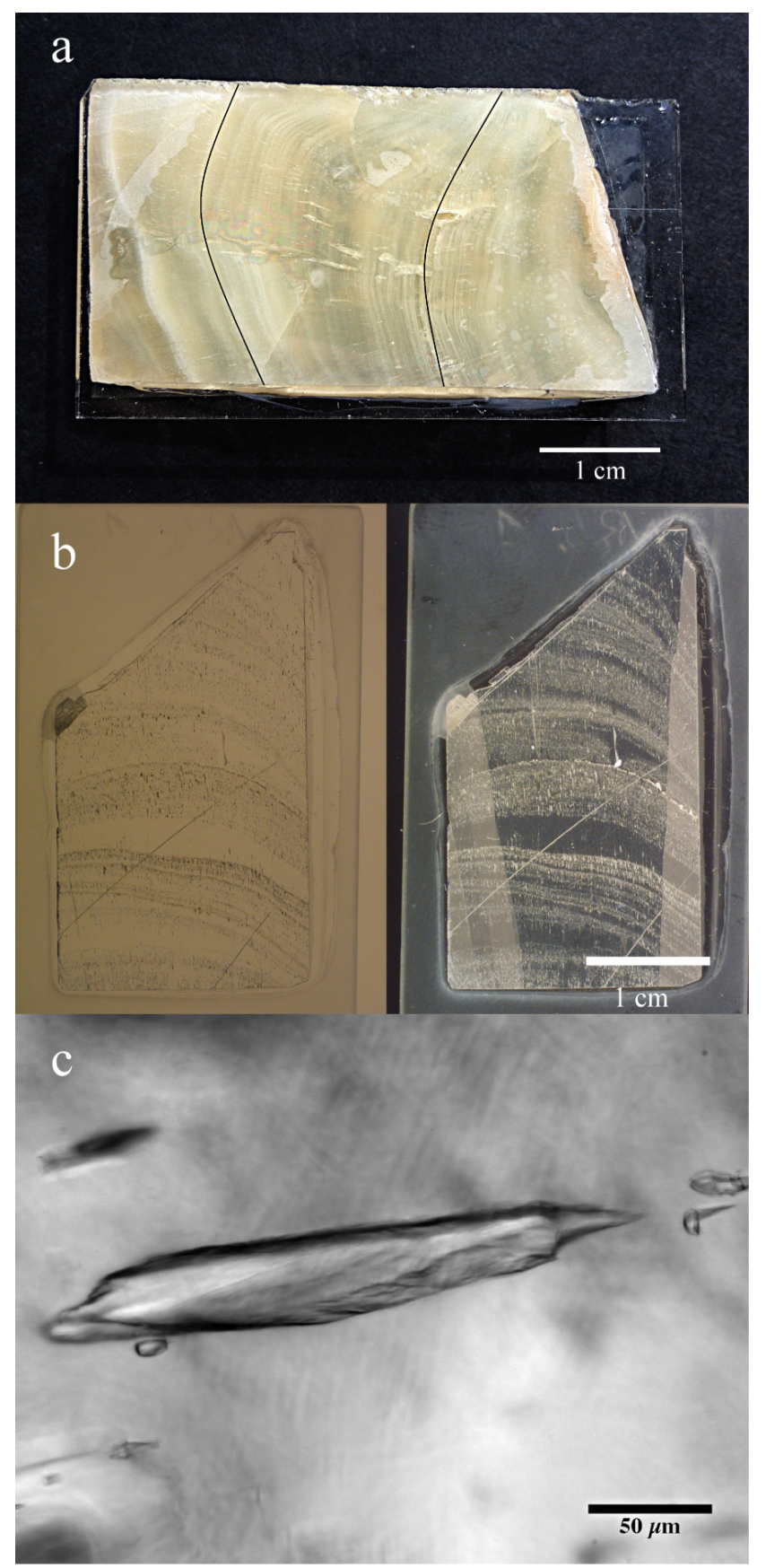

Figure 2. Speleothem sample. (a) Conditioning of the sample before being cut with a wire saw. Growth laminae are clearly visible. (b) Speleothem thin sections with their laminae. Fluid inclusions are visible in both cross-polarised (black) or bright field view (white). (c) Enlargement of single fluid inclusion.

tube has a volume of $\sim 11 \mathrm{~cm}^{3}$ and samples of up to $20 \mathrm{~mm}$ in length can be loaded. To avoid powder dissemination into the system, quartz wool is placed at both ends of the tube. The loaded tube is then quickly attached to the line using $1 / 4^{\prime \prime}$ and $3 / 8^{\prime \prime}$ Swagelok connections. 


\subsection{Desorption tests}

Atmospheric water vapour desorption of the sample can be a source of error in the water isotope analysis of speleothem fluid inclusions (Dennis et al., 2001) as the adsorbed atmospheric water present on the calcite surfaces can contaminate the released water after the crushing. Whilst it was recommended to operate fluid inclusion extraction at a temperature of $150{ }^{\circ} \mathrm{C}$, more recent studies (Vonhof et al., 2006; Dublyansky and Spötl, 2009) showed that temperatures of 120 to $130^{\circ} \mathrm{C}$ are sufficient to avoid desorption and adsorption problems. For systems working with a dry background, it is not only necessary to remove water adsorbed on the sample prior to crushing but also on all surfaces of the whole measuring system. With our analytical setup we only need to test the desorption efficiency from the speleothem sample surface. However, desorption tests were made in two steps. Firstly, we evaluate desorption from a stalagmite sample under dry nitrogen background conditions to characterise the phenomenon precisely and to estimate the total released water content. Secondly, we adapted the procedure to our normal measuring conditions in a humidified mode.

Desorption tests have been performed in the oven in which the loaded copper tube is positioned. The speleothem sample is placed at room temperature and flushed with dry nitrogen to the laser instrument for direct determination of desorbed water. With our setup, the nitrogen gas stream contains approximately $15 \mathrm{ppmv}$ of residual water. After the stabilisation and recovery of a dry background, the system is heated to $140{ }^{\circ} \mathrm{C}$ to evaluate how heating affects water desorption from the calcite (Fig. 3a). We performed five speleothem sample desorption measurements. Results of these tests show that the released amount of water varies between 0.06 and 0.13 microliter per gram of calcite. Dublyansky and Spötl (2009) showed that decrepitation of single inclusions during the heating of calcite can occur which is then clearly visible on a mass spectrometer spectrogram. So far we have not noticed such effects with our system.

The water vapour mixing ratio and the isotopic composition were monitored under measuring conditions (Fig. 3b). To minimise the migration of atmospheric water vapour into the system when a sample is loaded, the copper tube should be fixed rapidly to the heated line $\left(140^{\circ} \mathrm{C}\right)$. To ensure complete desorption of water adsorbed on the sample surface, the sample is heated until the background conditions are stable to a high degree, $\pm 0.25 \%$ ond $\pm 0.90 \%$ (if not the specified standard deviation of individual values is given), for $\delta^{18} \mathrm{O}$ and $\delta D$, respectively. This procedure typically takes $90 \mathrm{~min}$ before another sample measurement is processed. The time interval for the background determination is about $20 \mathrm{~min}$ (100 values), whereas uncertainties in the mean background are of the order of $\pm 0.03 \%$ and $\pm 0.1 \%$ ofor $\delta^{18} \mathrm{O}$ and $\delta D$, respectively. The background amount of water is fairly constant at $\pm 20 \mathrm{ppmv}$ for single values and $\pm 2 \mathrm{ppmv}$ for its
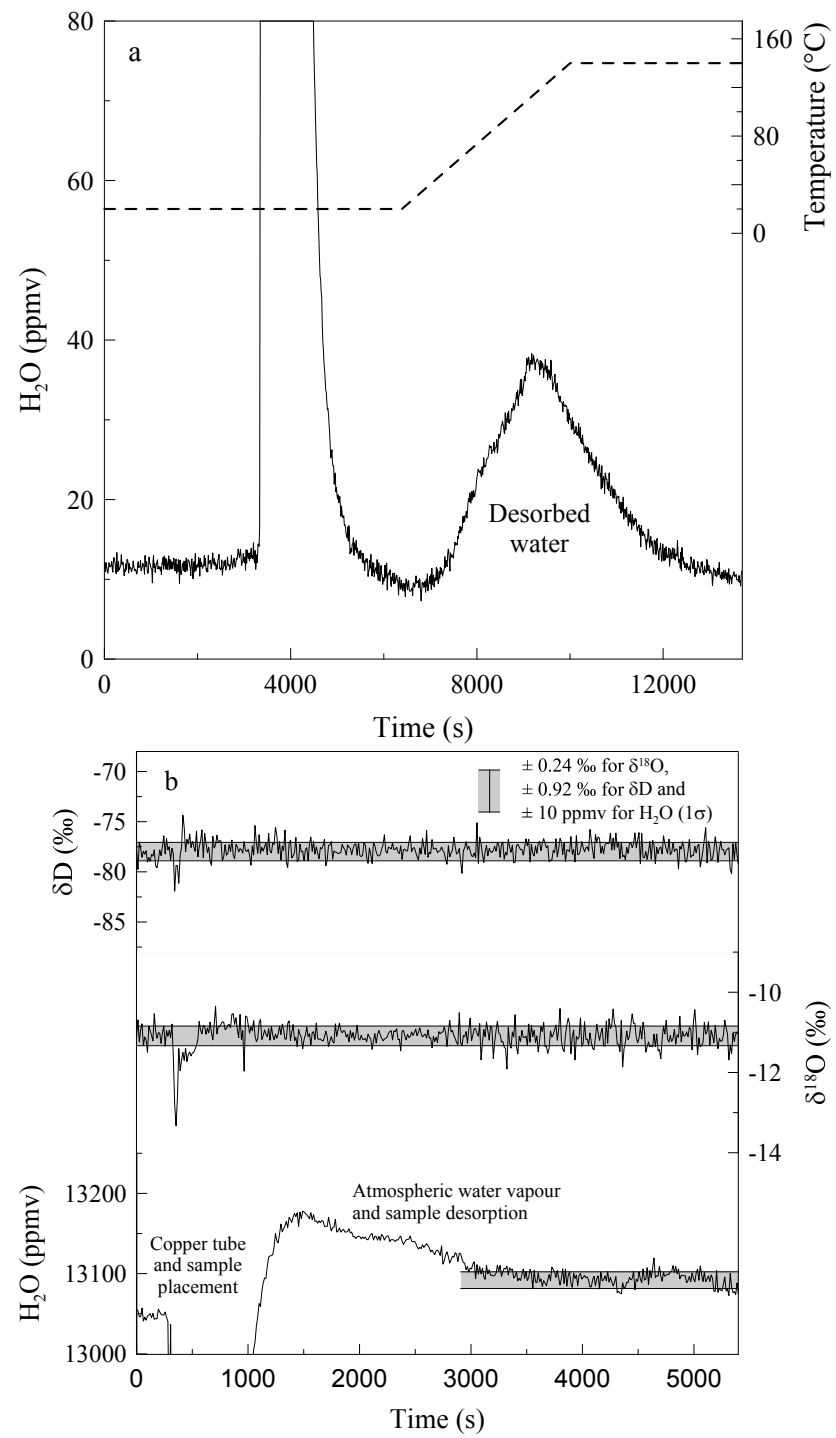

Figure 3. (a) Desorption test: The large peak corresponds to ambient water vapour migration during the opening of the line when loading the sample. After closing, the sample is flushed with a dry nitrogen stream without heating. After reaching the dry background level the system is heated to $140{ }^{\circ} \mathrm{C}$ to desorb the water from the calcite. (b) Example of desorption and stabilisation of water vapour amount and its isotopic composition after loading the sample. Desorption from the sample surface or from fluid inclusion cracks is hardly visible at this resolution.

mean. Such stable background conditions enhance the sample precision as discussed in detail in Sect. 2.4.2.

As the system is kept under humidified conditions, line walls are constantly conditioned with water molecules, and the probability of isotope exchange with adsorbed water at the walls is rather low since the mean free path length is small under our conditions. Therefore, it takes about $50 \mathrm{~min}$ to stabilise the background conditions. For speleothem sample measurements, $90 \mathrm{~min}$ were taken to ensure that no 
Table 1. Isotopic composition of internal standard waters used for calibration determined independently by IRMS.

\begin{tabular}{lrr}
\hline Standard & $\begin{array}{r}\delta^{18} \mathrm{O}(\mathrm{VSMOW}) \\
(\% \circ)\end{array}$ & $\begin{array}{r}\delta D(\mathrm{VSMOW}) \\
(\% \circ)\end{array}$ \\
\hline Meerwasser & $-0.044 \pm 0.05$ & $1.24 \pm 0.5$ \\
DOME_C & $-54.18 \pm 0.05$ & $-428.26 \pm 0.5$ \\
DYE-III & $-27.21 \pm 0.05$ & $-210.23 \pm 0.5$ \\
ST08 & $-10.79 \pm 0.05$ & $-77.46 \pm 0.5$ \\
\hline
\end{tabular}

atmospheric water vapour contamination will affect the measurement.

Though there are slightly different stability conditions between empty, loaded and crushed tube conditions, these different states may only slightly affect water background levels (as shown in Fig. 3b).

\subsection{Laser spectrometer calibration}

The use of the WS-CRDS system is new for this kind of application and the calibration and the precision of the Picarro L1102-i analyser has been determined carefully. The precision of the data will be discussed in Sect. 4. In this section, we present tests that are relevant for optimising the continuous measurements using our online system (coupling of preconditioning/crusher/laser instrument). Table 1 gives the isotopic composition of standard waters used for the calibration.

\subsubsection{Isotopic calibration for water vapour measurements}

Three standards (Meerwasser, ST-08 and DYE-III) have been used to perform the isotopic calibration of the instrument against the VSMOW scale. Their isotopic values were precisely measured in our institute by mass spectrometry and they ranged from $0 \%$ to $-27 \%$ for $\delta^{18} \mathrm{O}$ and from $0 \%$ to $-220 \%$ for $\delta D$. These waters fit with the expected range of values of fluid inclusion water in speleothems. Injection of each standard via the peristaltic pump into the dripping device lasts at least three hours to ensure that the system reaches an equilibrium state. The correlation between the measured ( $x$ value) and the assigned value ( $y$ value) is used as the instrument correction equation. For this study the corrected isotopic value for $\delta^{18} \mathrm{O}$ is $y=0.989 x( \pm 0.001)+0.112( \pm 0.021)\left(r^{2}=1\right)$ and for $\delta D$ it is $y=0.965 x( \pm 0.002)-0.574( \pm 0.299)\left(r^{2}=1\right)$. These equations need to be updated depending on the instrument performance and they are applied to all isotopic data recorded by the laser instrument in order to get the most accurate isotopic composition of the sample.

\subsubsection{Optimising a stable water background}

Laser spectroscopy under dry conditions (water background 10 to $100 \mathrm{ppmv}$ ) results in highly variable $\delta D$ and $\delta^{18} \mathrm{O}$ isotopic background values of $\pm 1000 \%$ for $\delta D$ and $\pm 250 \%$ for $\delta^{18} \mathrm{O}$, which hampers obtaining reliable data. Furthermore, when working close to dry conditions water molecules have a tendency to stick to the line surface and fractionation may occur. This is particularly important for small amounts of water, as is the case in our application. To avoid such an effect, we decided to admix standard water continuously with a known isotopic composition to generate an artificial water background that is close to the best operational domain of the analyser (17000 to $23000 \mathrm{ppmv}$ ). This implies that during the entire measuring procedure, the surfaces of the device are saturated with standard water molecules to avoid this volatility problem that is well known for dry conditions.

As a working reference for the speleothem fluid inclusion measurement we use an internal standard water (ST08 ). To evaluate the stability of the system over a workday, a $13 \mathrm{hr}$ continuous admixture of ST-08 has been established. Results show that the water vapour mixing ratio in the optical cavity cell reached $13462 \pm 32$ ppmv $(1 \sigma)$. Similarly, the isotopic stability reaches $-77.31 \pm 0.58 \%$ for $\delta D$ and $-10.93 \pm 0.12 \%$ for $\delta^{18} \mathrm{O}$.

The dependence of isotope ratios on the mixing ratio was evaluated by varying the mixing ratio for eleven individual levels between 6700 and 20500 ppmv. Data were recorded for each level for $\sim 40 \mathrm{~min}$ and data analyses were made during the last $20 \mathrm{~min}$ (Table 2). Standard deviation is robust for $\delta^{18} \mathrm{O}( \pm 0.10 \%$ ) between 13000 and 19000 ppmv and only slightly enhanced below and above this range (Fig. 4). For $\delta D$, standard deviation decreases continuously from $1.1 \%$ o to $0.5 \%$ o between 7000 and $13000 \mathrm{ppmv}$ and then stabilises below $0.5 \%$ up to 22000 ppmv. The stability of the water background is \pm 10 ppmv below 14000 ppmv and increases up to \pm 30 ppmv above it. The reproducibility of the individual isotope measurements for $\delta D$ increases with the increasing mixing ratios, but remains stable for $\delta^{18} \mathrm{O}$ (Fig. 5). The absolute values for $\delta D$ show a decrease with increasing mixing ratios and then a constant behaviour over $13000 \mathrm{ppmv}$, whereas $\delta^{18} \mathrm{O}$ values increase with rising mixing ratios up to 12000 ppmv and are rather stable thereafter. Based on these observations we decided to perform the measurements with a background mixing ratio of $\sim 13000 \pm 1000 \mathrm{ppmv}$.

\subsubsection{Time needed for system stabilisation}

The stabilisation time after replacing an empty copper tube with a loaded one can be evaluated by monitoring both isotope values and water vapour mixing ratios. To do so, three experiments were conducted: (i) with an empty tube, (ii) with a speleothem sample loaded tube and finally (iii) with a crushed sample. Figure 6 shows the response time of the 
Table 2. Effect of the water vapour mixing ratio on $\delta D$ and $\delta^{18} \mathrm{O}$ measurement vs. VSMOW based on 40 min measuring intervals per water level.

\begin{tabular}{lccccc}
\hline $\begin{array}{l}\text { Water vapour mixing } \\
\text { ratio (ppmv) }\end{array}$ & $\begin{array}{c}\text { Standard deviation } \\
(\mathrm{ppmv})\end{array}$ & $\begin{array}{c}\delta^{18} \mathrm{O} \\
(\% \circ)\end{array}$ & $\begin{array}{c}\text { Standard deviation } \\
(\% \circ)\end{array}$ & $\begin{array}{c}\delta D \\
(\% \circ)\end{array}$ & $\begin{array}{c}\text { Standard deviation } \\
(\% \circ)\end{array}$ \\
\hline 6717 & 5 & -11.44 & 0.13 & -77.41 & 1.01 \\
8000 & 5 & -11.36 & 0.11 & -77.48 & 0.78 \\
9520 & 6 & -11.23 & 0.11 & -77.83 & 0.67 \\
10810 & 5 & -11.18 & 0.11 & -78.08 & 0.62 \\
12093 & 6 & -11.16 & 0.11 & -78.04 & 0.54 \\
13414 & 8 & -11.13 & 0.10 & -78.32 & 0.46 \\
15016 & 29 & -11.12 & 0.09 & -78.34 & 0.50 \\
16365 & 28 & -11.06 & 0.10 & -78.40 & 0.51 \\
17698 & 22 & -11.07 & 0.10 & -78.45 & 0.40 \\
18968 & 15 & -11.04 & 0.10 & -78.44 & 0.48 \\
20476 & 35 & -11.12 & 0.11 & -78.45 & 0.45 \\
\hline
\end{tabular}

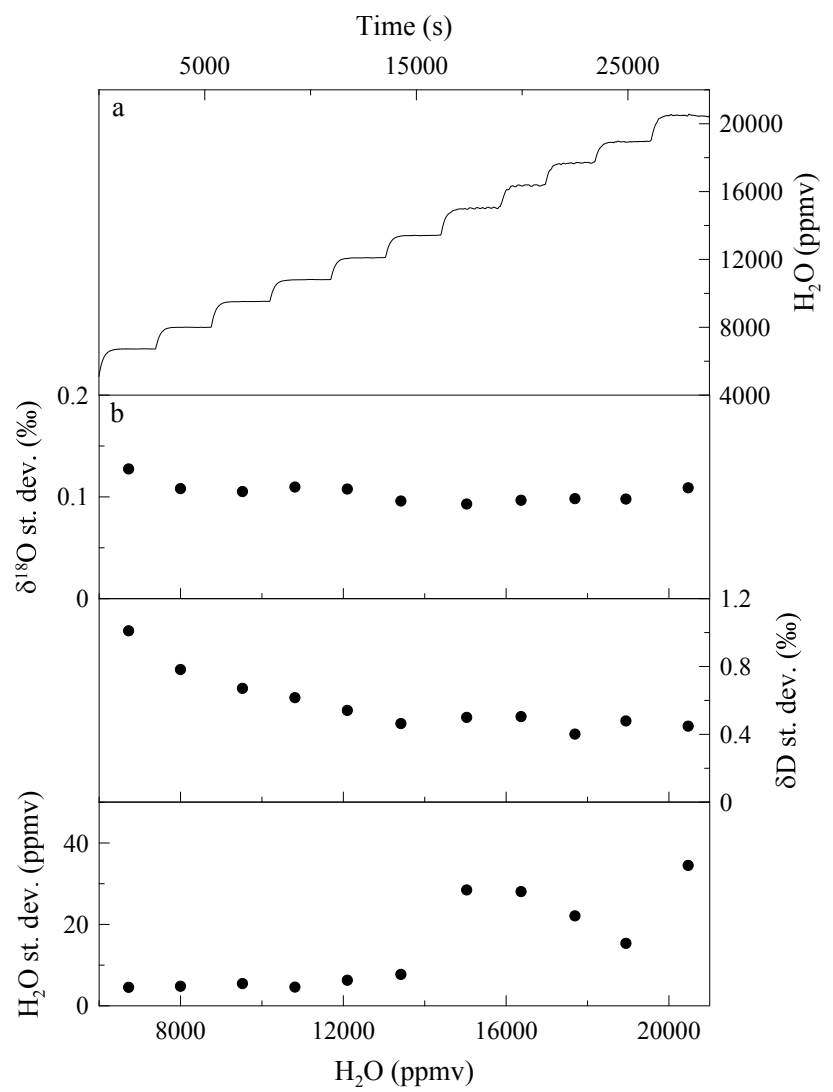

Figure 4. $\delta^{18} \mathrm{O}$ and $\delta D$ reproducibility with changing water vapour amounts. (a) Water vapour mixing ratios were increased by changing the speed of the pump in steps of $0.2 \%$ from 1 to $3 \%$ of its capacity. (b) Evolution of the standard deviation of the water vapour isotopic measurement for $\delta D$ and $\delta^{18} \mathrm{O}$ and water vapour amount as a function of the water vapour amount.

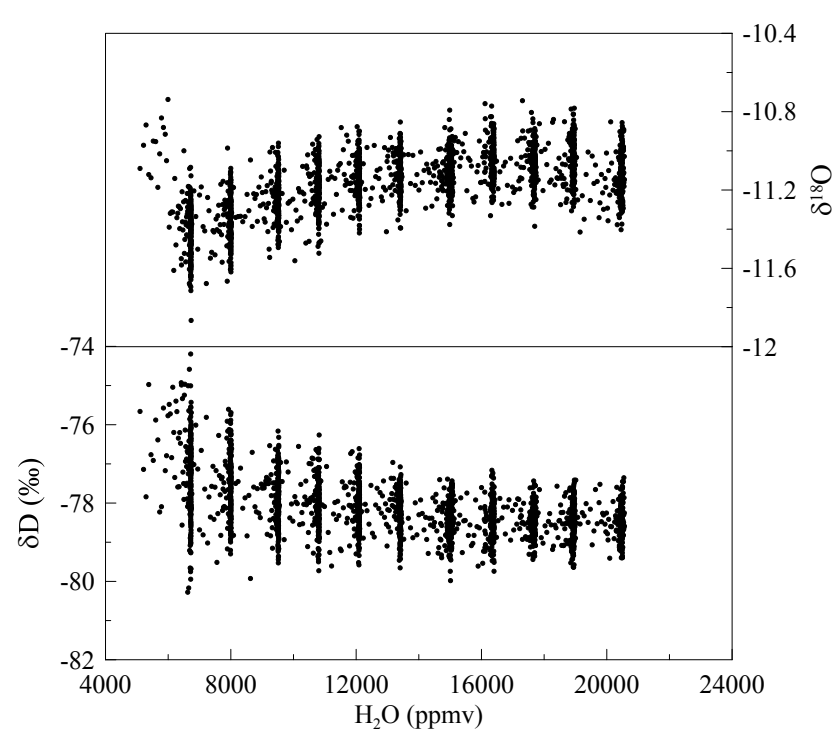

Figure 5. $\delta^{18} \mathrm{O}$ and $\delta D$ dependence on injected water vapour amounts presented in Fig 4 .

system after switching between two standards (from ST-08 to DOME-C). For the three experiments, the system behaves in the same way as documented by the three resulting isotope traces. There are no significant offsets in the delta values as a function of time, suggesting that the presence of material in the tube has no significant influence on the time needed for the system to stabilise when switching between two isotopically different waters. Approximately 45 and 75 min are necessary to stabilise $\delta^{18} \mathrm{O}$ and $\delta D$, respectively.

\subsection{Measurement protocol}

To achieve precise and reproducible measurements, several tests have been made to optimise the measurement protocol (Fig. 7). Once a stable background is reached, a first 

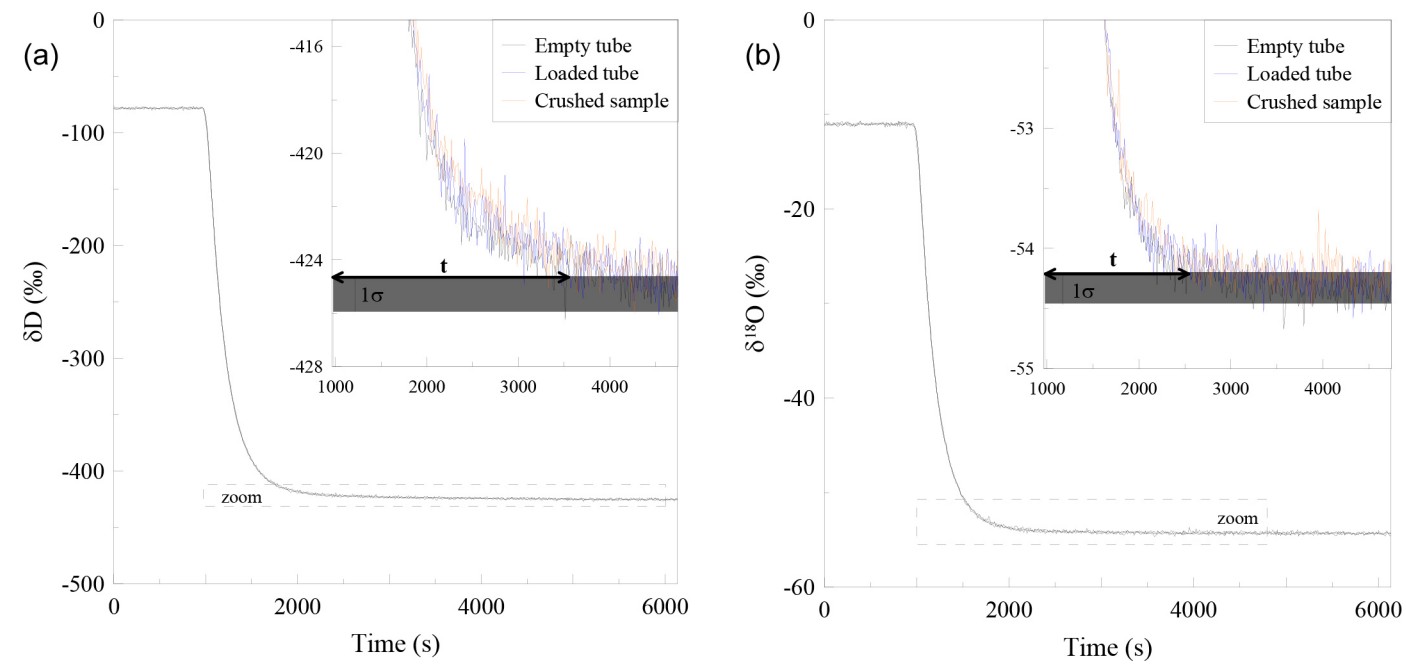

Figure 6. System response for switching from ST-08 to DOME-C standard water. No difference is noticeable for empty, loaded or crushed tube conditions.

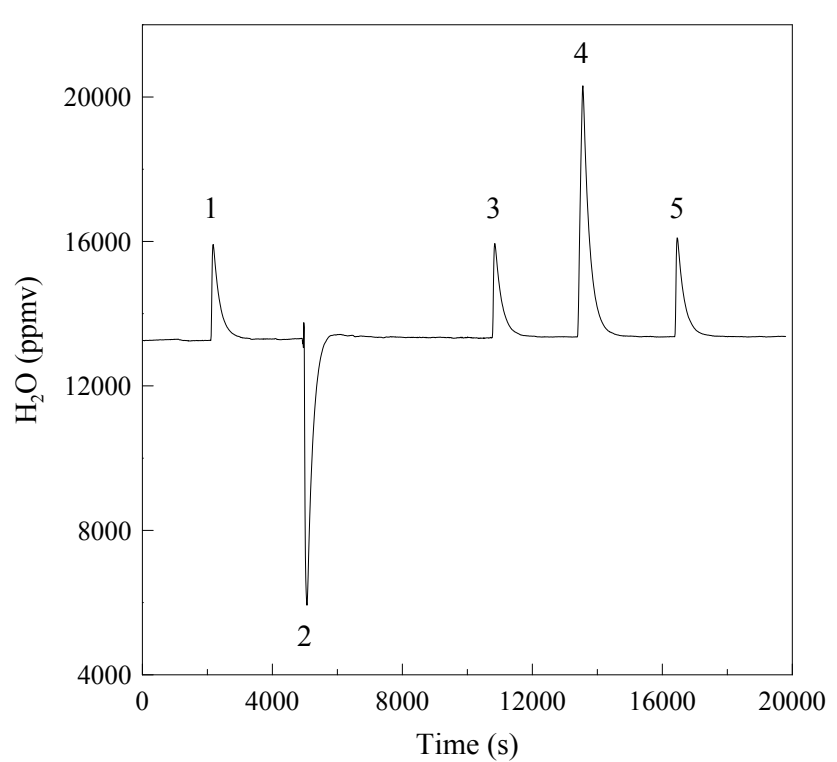

Figure 7. Water vapour evolution during a measurement sequence. Peaks 1,3 and 5 are $0.5 \mu$ injections of ST-08 standard water. Peak 4 corresponds to the released fluid inclusion water. Depression 2 corresponds to the exchange between the empty and the loaded copper tube.

$0.5 \mu$ internal standard (ST-08) is injected manually (peak 1 in Fig. 7). After $40 \mathrm{~min}$, the empty tube is then quickly exchanged (within 30s) with the copper tube containing a sample (peak 2) to minimise ambient water vapour contamination. We wait for approximately $90 \mathrm{~min}$ to be sure to restore the original conditions including the removal of adsorbed water from the sample. Insufficient time could lead to a mixture of background standard water with adsorbed atmospheric water vapour. Once a stable background is reached again (water vapour mixing ratio and isotopic composition), a second standard ST-08 reference peak is injected (peak 3, Fig. 7). After $40 \mathrm{~min}$, the speleothem sample is crushed (peak 4, Fig. 7) and the released fluid inclusions water reaches the Picarro analyser approximately $40 \mathrm{~s}$ later. After up to $60 \mathrm{~min}$ (depending on the water amount released from the sample) a last standard water aliquot is injected on the crushed calcite (peak 5, Fig. 7). 40 min later the measurement sequence is terminated. These three standard peaks allow us to control the stability of the measurement. The overall time needed to run one speleothem sample using the described method (Fig. 7) is approximately five hours, of which the sample peak itself lasts only around $20 \mathrm{~min}$. In a time-optimised procedure a minimal time of $2 \mathrm{hr}$ for one sample is necessary to guarantee the stated precision.

\section{Raw data evaluation}

The analyser software records all measured parameters at intervals of $\sim 12.2 \mathrm{~s}$ (Fig. 8). The water vapour mixing ratio value can be used as it is recorded, whereas $\delta D$ and $\delta^{18} \mathrm{O}$ need to be corrected using a linear correlation that is obtained by measuring various standard waters with known isotopic values as shown in Sect. 2.4.1.

\subsection{Estimation of sample water concentration}

The released amount of sample water is determined as follows: various aliquots of water ranging from 0.02 to $2 \mu \mathrm{l}$ were injected on a wet background to determine the associated signal area $S_{\mathrm{A}}$ (Eq. 1a) or maximal signal amplitude $S_{\mathrm{M}}$ (Eq. 1b). They are then used to determine the amount of water released through crushing the sample with a precision 


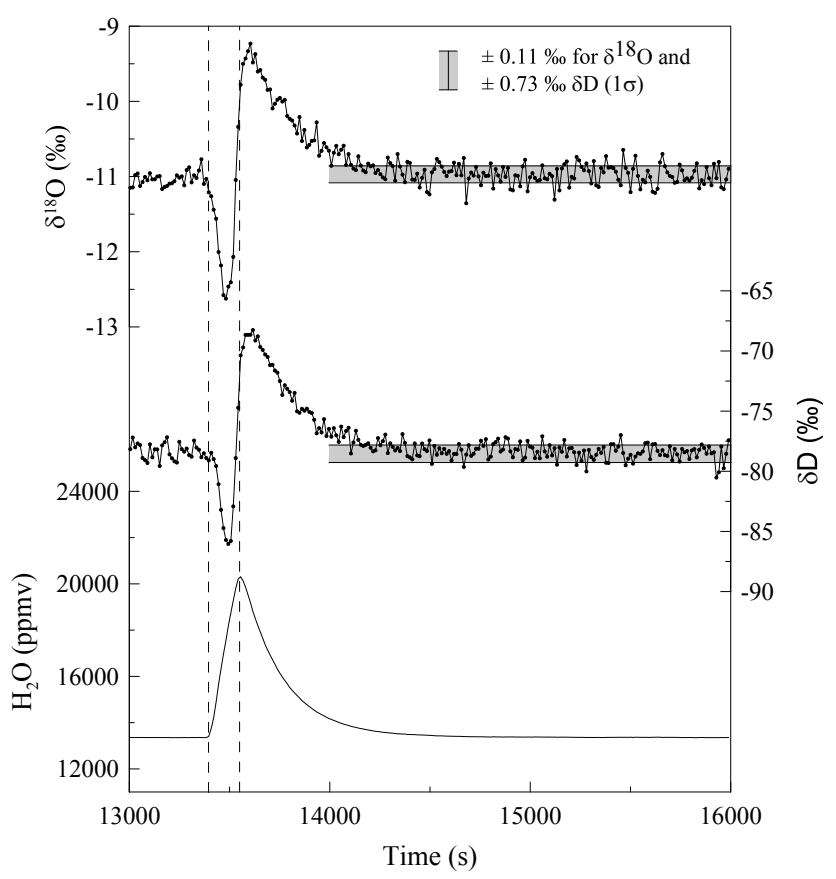

Figure 8. These spectrograms show the $\delta^{18} \mathrm{O}, \delta D$ and $\mathrm{H}_{2} \mathrm{O}$ responses of the Picarro for a speleothem sample measurement (Fig. 7, peak 4). Both isotope ratios behave similarly. Due to diffusional fractionation of the light and heavy water isotopologues during the sample transfer by nitrogen, depleted values are observed for the very first part of the sample. Maximal isotope values are reached after the maximum of the water amount. The signals reach background stability again after about $20 \mathrm{~min}$.

of $\pm 0.08 \mu \mathrm{l}$ for $S_{\mathrm{A}}$ and $\pm 0.10 \mu$ for $S_{\mathrm{M}}$ (Fig. 9):

$$
\begin{aligned}
& \mathrm{H}_{2} \mathrm{O}[\mu \mathrm{L}]=7.16 \times 10^{-7} \cdot S_{\mathrm{A}}+0.0244 \\
& \mathrm{H}_{2} \mathrm{O}[\mu \mathrm{L}]=9.50 \times 10^{-9} \cdot S_{\mathrm{M}}^{2}+0.000152 \cdot S_{\mathrm{M}}+0.0187 .
\end{aligned}
$$

The sample water concentration $(c)$ is obtained by dividing Eq. (1a) by the sample weight $(\mathrm{m})$.

$c=\frac{\mathrm{H}_{2} \mathrm{O}[\mu \mathrm{L}]}{m[\mathrm{~g}]}$

\subsection{Calculation of $\delta D$ and $\delta^{18} O$ isotopic values}

When the sample is crushed, standard and sample waters with different isotopic compositions are mixed in the line. To determine the isotopic composition of the sample we integrate the product of the water amount and its isotopic value over the entire peak. However, we need to take into account the background (Fig. 10).

As the software delivered with the Picarro cannot be used for this measurement procedure, we developed a simple data evaluation protocol to calculate the isotopic composition of the standard or speleothem fluid inclusion water. A criterion for peak integration is determined on the basis of the water content. The peak inflection point is well defined as the

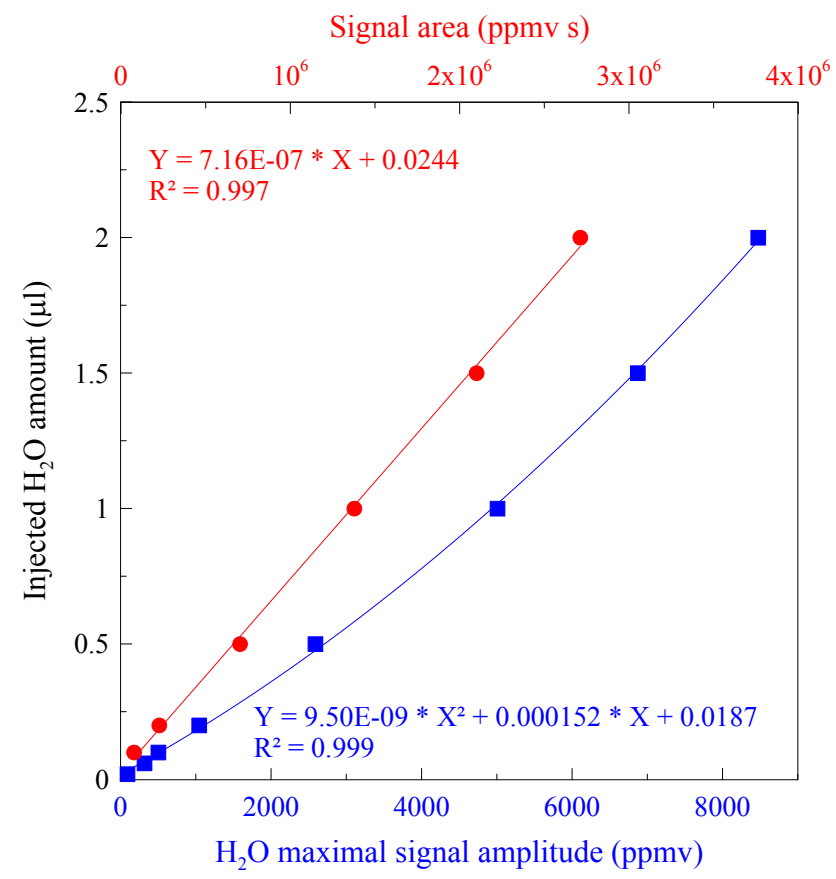

Figure 9. The relationship between the sample signal and the injected water amount for the vapour is used to calibrate the released water amount from fluid inclusions. Calibration was determined for amounts up to $2 \mu \mathrm{l}$ using a wet background and based on two schemes: (i) with the signal area converted into water amounts (linear regression in red) and (ii) relative to the maximal signal intensity (polynomial regression in blue).

released (or injected) water leads to a rapid increase in the water vapour mixing ratio; more specifically the criterion for the peak starting time $\left(t_{0}\right)$ is defined by $\mathrm{dH}_{2} \mathrm{O}(t) / \mathrm{d} t \geq$ 2 ppmv s $^{-1}$.

Fractionation occurs right after the peak inflection point and after the peak maximum the mixing ratio will decrease slowly with time. As mentioned before, with this setup a peak lasts $\sim 20 \mathrm{~min}$. The criterion used to determine the peak end time $\left(t_{1}\right)$ is $\mathrm{dH}_{2} \mathrm{O}(t) / \mathrm{d} t \geq-0.15 \mathrm{ppmv} \mathrm{s}^{-1}$. Precise peak definition is especially crucial when small water amounts are being measured.

The general equation for the water mixture amount is

$\mathrm{H}_{2} \mathrm{O}_{\text {mix }}=\mathrm{H}_{2} \mathrm{O}_{\mathrm{s}}+\mathrm{H}_{2} \mathrm{O}_{\mathrm{b}}$,

where $s$ and $b$ stand for the sample and the background, respectively. The same can be applied to heavy-oxygen water:

$\mathrm{H}_{2}^{18} \mathrm{O}_{\text {mix }}=\mathrm{H}_{2}^{18} \mathrm{O}_{\mathrm{s}}+\mathrm{H}_{2}^{18} \mathrm{O}_{\mathrm{b}}$.

With Eqs. (4)/(3) and approximating $\mathrm{H}_{2} \mathrm{O}_{\text {mix }}=\mathrm{H}_{2}^{16} \mathrm{O}_{\text {mix }}+$ $\mathrm{H}_{2}^{18} \mathrm{O}_{\text {mix }}$ with $\mathrm{H}_{2}^{16} \mathrm{O}_{\text {mix }}\left(\mathrm{H}_{2}^{18} \mathrm{O}_{\text {mix }}\right.$ contributes only $\left.0.2 \%\right)$, we have $\mathrm{H}_{2}^{18} \mathrm{O}_{\text {mix }} / \mathrm{H}_{2} \mathrm{O}_{\text {mix }} \approx \mathrm{H}_{2}^{18} \mathrm{O}_{\text {mix }} / \mathrm{H}_{2}^{16} \mathrm{O}_{\text {mix }}$. 


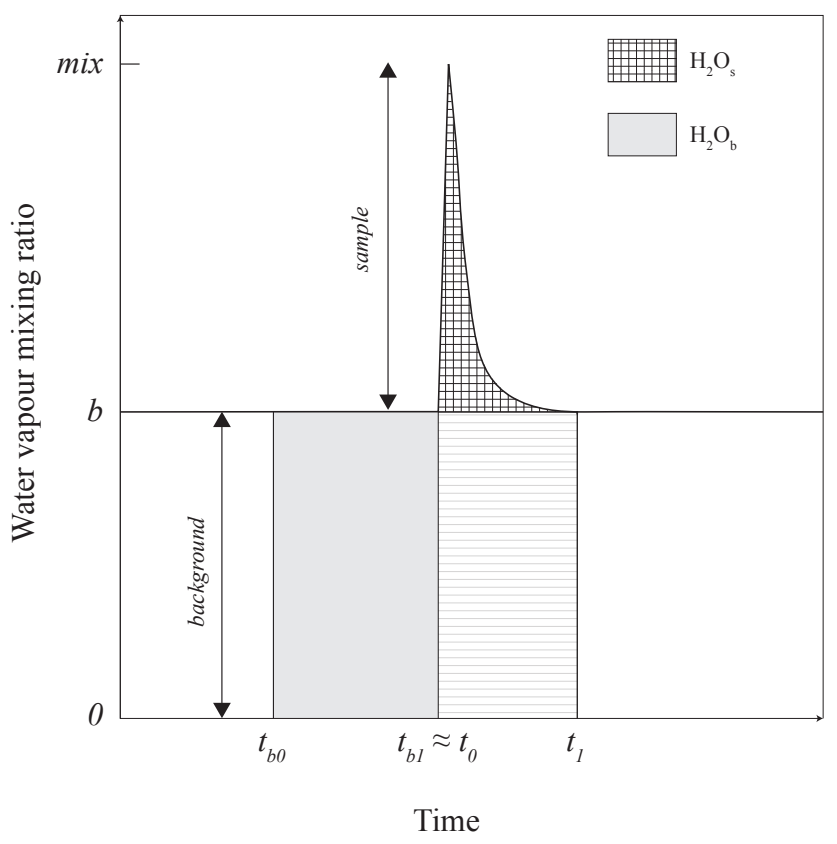

Figure 10. Schematic diagram illustrating the evaluation protocol (see text for details).

The isotope values in Delta notation can be calculated as follows:

$\overline{\delta^{18} \mathrm{O}_{j}}=\frac{\int_{t_{0}}^{t_{1}} \delta^{18} \mathrm{O}_{j}(t) \cdot \mathrm{H}_{2} \mathrm{O}_{j}(t)}{\int_{t_{0}}^{t_{1}} \mathrm{H}_{2} \mathrm{O}_{j}(t)}$

$\overline{\mathrm{H}_{2} \mathrm{O}_{j}}=\frac{\int_{t_{o}}^{t_{1}} \mathrm{H}_{2} \mathrm{O}_{j}(t) \mathrm{d} t}{\int_{t_{o}}^{t_{1}} \mathrm{~d} t}=\frac{\int_{t_{o}}^{t_{1}} \mathrm{H}_{2} \mathrm{O}_{j}(t) \mathrm{d} t}{t_{1}-t_{0}}$

where $j$ is either the mixture, the background or the sample.

To calculate the isotopic value of a sample $\delta_{s}$ of the injected or released water we use the following relationship.

$\delta_{\mathrm{s}}=\frac{\overline{\delta^{18} \mathrm{O}_{\text {mix }}} \cdot \overline{\mathrm{H}_{2} \mathrm{O}_{\text {mix }}}-\overline{\delta^{18} \mathrm{O}_{\mathrm{b}}} \cdot \overline{\mathrm{H}_{2} \mathrm{O}_{\mathrm{b}}}}{\overline{\mathrm{H}_{2} \mathrm{O}_{\text {mix }}}-\overline{\mathrm{H}_{2} \mathrm{O}_{\mathrm{b}}}}$

For $\delta D$, we used a correspondent evaluation.

\section{Reproducibility tests}

\subsection{Water injections}

To test the new setup three different internal standards were analysed to ensure good accuracy and precision of the line. A total of 46 manual injections of standard water of $1,1.5$ and $2 \mu \mathrm{l}$ were performed. The three known isotopic standards ranged between $0.63 \%$ and $-429.39 \%$ or $\delta D$ and between $-0.11 \%$ and $-54.23 \%$ or for $\delta^{18} \mathrm{O}$. The reproducibility test of these standard waters (Meerwasser, DYE-III and DOME-C) is summarised in Table 3 and Fig. 11.

For $\delta^{18} \mathrm{O}$, measurements are rather accurate and precise over the entire range between 0 and $-55 \%$. However, standard deviations are slightly influenced by the water amount and the Delta value, both resulting in a change in the spectral signal strength of the laser system. The lower the water amount and the lower Delta value the smaller the spectral signal for the less abundant isotope gets. This is clearly visible for samples with very negative $\delta D$ values (DOME-C water), for which we receive a clear decrease in precision but retain accuracy. Therefore, the standards used for calibrating the whole setup should represent the expected range of sample Delta values.

\subsection{Speleothem samples}

For fluid inclusion analysis, a total of twelve samples from four different layers of stalagmite WR5 (Whiterock cave) from northern Borneo in the tropical West Pacific covering the time period between MIS 12 to early MIS 9 (460-330 ka) (Meckler et al., 2012) were analysed (Fig. 12). Each sample was split into several pieces of between 100 and 200 milligrams each to run three replicates. The results of the $\delta D$ and $\delta^{18} \mathrm{O}$ measurements and water amounts are summarised in Table 4. The released water amounts range from 0.4 to $2.2 \mu \mathrm{l}$ and correspond to water contents between 2 and 19 microliter per gram of calcite (average of $10.1 \mu \mathrm{g} \mathrm{g}^{-1}$ ). The calculated water concentration between the three replicates is not constant (except for sample 387). This is most probably due to the unequally distributed fluid inclusions in the stalagmite and we expect the influence of the crushing to be minimal since the grain size distribution is rather constant. The released water amounts do not have a strong influence on the isotope values measured. Nevertheless, the sample weight should be selected so that the released water amount is at least $0.5 \mu \mathrm{l}$ or higher. In addition, two fluid inclusion analyses were made for a recent speleothem sample (stalagmite M6) from Milandre cave (Switzerland), where the corresponding modern drip water is also monitored. Stalagmite M6 was actively growing and the measurement corresponds to a mixture of fluid inclusions comprising the last 40 years. The sample grows exactly under the stalactite where drip water was collected and monitored. The collection was made on a three-month interval during the last two years and 
Table 3. Experimental results with injected aliquots of standard water (refer to Table 1 for uncertainties in the expected values). Note that the aliquots slightly deviate from values given in Table 1.

\begin{tabular}{llcrrrr}
\hline Standard & Injected amount & $\begin{array}{c}\text { Number of } \\
\text { injections } \\
(n)\end{array}$ & $\begin{array}{r}\delta^{18} \mathrm{O} \text { average } \\
(\% \circ)\end{array}$ & $\begin{array}{c}\text { Standard } \\
\text { deviation } \\
(\%)\end{array}$ & $\delta D$ average & $\begin{array}{c}\text { Standard } \\
\text { deviation } \\
(\%)\end{array}$ \\
\hline Meerwasser & 2 & 6 & 0.3 & 0.1 & -1.0 & 0.3 \\
& 1.5 & 5 & 0.3 & 0.3 & -1.1 & 0.7 \\
& 1 & 5 & 0.2 & 0.2 & -0.8 & 1.5 \\
& Expected values & & -0.1 & & 0.6 & \\
DYE-III & 2 & 5 & -27.1 & 0.2 & -212.6 & 0.4 \\
& 1.5 & 5 & -27.1 & 0.3 & -211.5 & 0.7 \\
& 1 & 4 & -27.1 & 0.1 & -212.1 & 0.7 \\
& Expected values & & -27.3 & & -212.8 & \\
DOME-C & 2 & 5 & -54.3 & 0.3 & -429.7 & 2.0 \\
& 1.5 & 5 & -54.4 & 0.2 & -430.1 & 2.1 \\
& 1 & 6 & -54.2 & 0.7 & -428.7 & 4.2 \\
& Expected values & & -54.2 & & -429.4 & \\
\hline
\end{tabular}
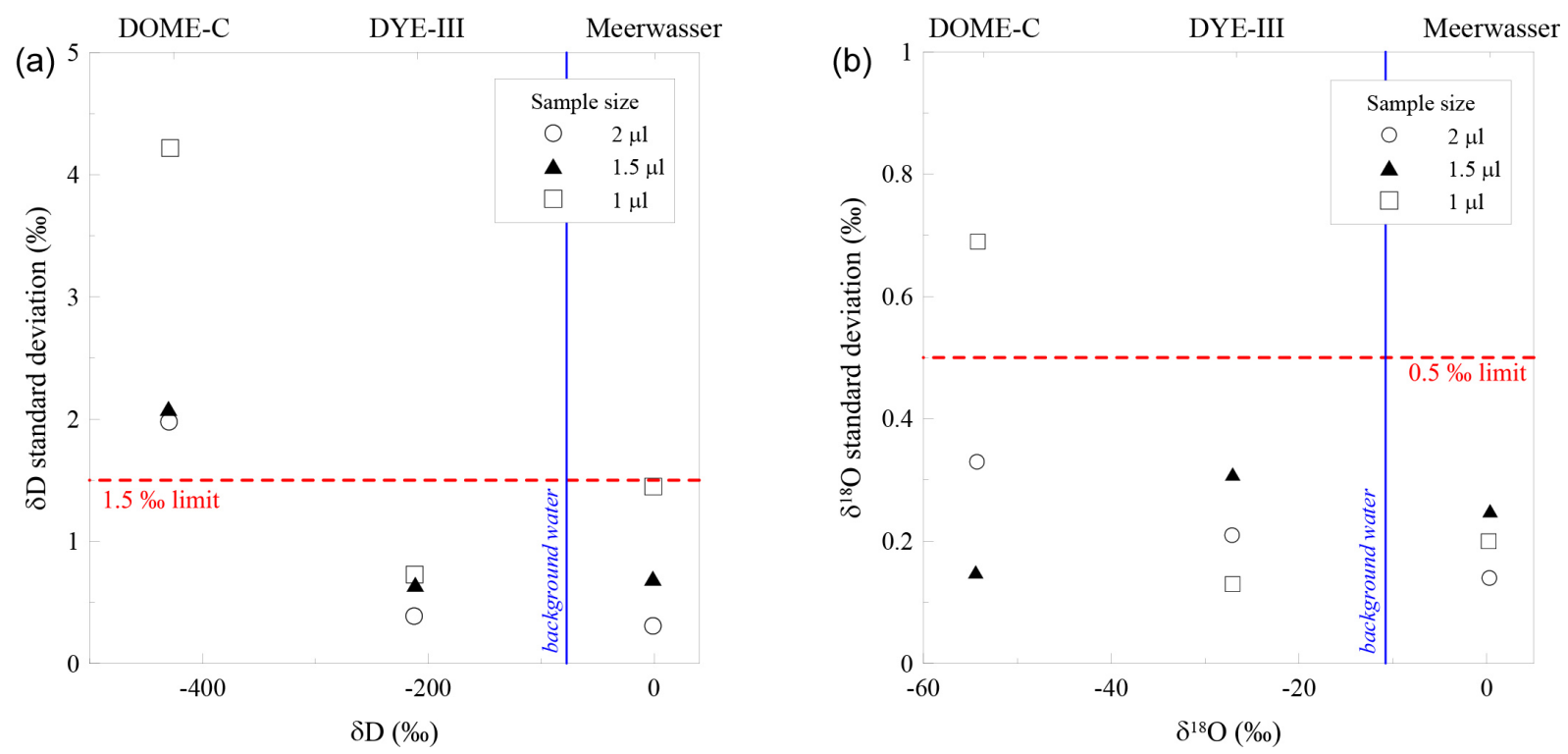

Figure 11. Summary of the reproducibility tests made for different standard waters ranging from 0 to $-450 \%$ for $\delta D$ (left panel) and from 0 to $-55 \%$ o for $\delta^{18} \mathrm{O}$ (right panel).

the isotopic composition of the drip water shows fairly small variations ranging between $-8.71 \%$ and $-9.20 \%$ in $\delta^{18} \mathrm{O}$. Samples weighing between 800 and 900 milligrams were crushed, releasing a constant water amount of $0.6 \mu \mathrm{l}$ (average water concentration of $0.68 \mu \mathrm{g} \mathrm{g}^{-1}$ ). The observed isotopic offset between drip and fluid inclusion water is around $1 \%$ for $\delta^{18} \mathrm{O}$, while $\delta D$ values are identical. This might indicate a postdepositional exchange between calcite and inclusion water or it could document a kinetic fractionation (similar in magnitude for both oxygen and hydrogen isotopes) during the enclosure of the fluid inclusion water. The latter would be easily observable for $\delta^{18} \mathrm{O}$ within its uncertainty of
$0.4 \%$, but not for $\delta D$ due to its larger uncertainty of $1.5 \%$. Results are given in Table 5 .

\section{Conclusions}

We present a new system for measuring hydrogen and oxygen isotope ratios of fluid inclusions water extracted from speleothems. The measuring principle is based on the wavelength-scanned cavity ring-down spectroscopy technology that allows simultaneous monitoring of hydrogen and oxygen isotopes. The main advantages of the WSCRDS technique in relation to our study are that (i) this 


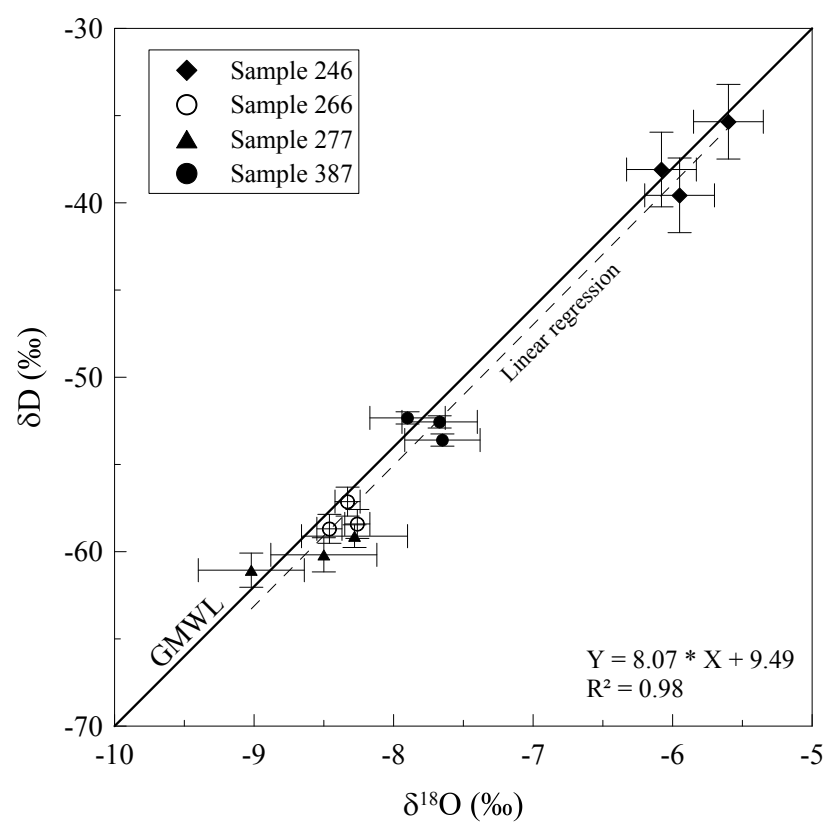

Figure 12. $\delta D$ vs. $\delta^{18} \mathrm{O}$ measurements with standard deviations based on three replicates for speleothem samples from Borneo. Results are close to the Global Meteoric Water Line (GMWL), which is similar to the meteoric water line of Borneo (Moerman et al., 2013).

instrument is only dedicated to water isotope measurement, (ii) the operational costs of the analysis are low and (iii) the speleothem fluid inclusion measurement procedure is simplified by avoiding any water treatment prior to their isotopic determination, such as the reduction of $\mathrm{H}_{2} \mathrm{O}$ in a pyrolysis reactor into $\mathrm{CO}$ and $\mathrm{H}_{2}$ molecules as is required for the combination of gas chromatography (cleaning of the products) and IRMS method (isotope detection unit). Moreover, the line avoids the step of the freezing treatment using a cryofocusing cell.

The new simple and easy-to-build line allows one to extract and analyse the isotopic composition of water released from speleothem fluid inclusions by crushing the sample with a hydraulic press. This line could even be used for air inclusions not discussed here.

With this setup, we achieve standard deviations smaller than $1.5 \%$ or for $\delta D$ (between 0 and $-210 \%$ at least) and $0.4 \%$ for $\delta^{18} \mathrm{O}$ (between 0 and $-27 \%$ at least) for sample sizes from and above $1 \mu \mathrm{l}$, comparable with traditional IRMS measurements. These isotopic intervals are wide enough for our speleothem target measurement. For more negative values, measurements are still possible, with lower precision but retained accuracy (especially for $\delta D$ ). It is best to adjust the isotope value of background water and the calibration waters to the target range (expected sample values). The reproducibility for real stalagmite samples was in the same range even for small-sized sample amounts of the order of $0.5 \mu$.
Table 4. Experimental results with crushed speleothem samples from Borneo.

\begin{tabular}{|c|c|c|c|}
\hline Sample & $\begin{array}{r}\delta^{18} \mathrm{O} \\
(\% o)\end{array}$ & $\begin{array}{r}\delta D \\
(\% o)\end{array}$ & $\begin{array}{c}\text { Released water } \\
(\mu \mathrm{L})\end{array}$ \\
\hline $246-1$ & -5.6 & -35.4 & 1.99 \\
\hline $246-2$ & -6.1 & -38.1 & 0.95 \\
\hline $246-3$ & -6.0 & -39.6 & 2.04 \\
\hline Average & -5.9 & -37.7 & \\
\hline Standard deviation & 0.3 & 2.1 & \\
\hline $266-1$ & -8.5 & -58.7 & 2.18 \\
\hline $266-2$ & -8.3 & -58.4 & 1.87 \\
\hline $266-3$ & -8.3 & -57.1 & 1.86 \\
\hline Average & -8.4 & -58.1 & \\
\hline Standard deviation & 0.1 & 0.8 & \\
\hline $277-1$ & -8.5 & -60.2 & 1.34 \\
\hline $277-2$ & -9.0 & -61.1 & 0.44 \\
\hline $277-3$ & -8.3 & -59.1 & 0.62 \\
\hline Average & -8.6 & -60.1 & \\
\hline Standard deviation & 0.4 & 1.0 & \\
\hline $387-1$ & -7.7 & -53.6 & 1.95 \\
\hline $387-2$ & -7.9 & -52.3 & 1.79 \\
\hline $387-3$ & -7.7 & -52.6 & 2.23 \\
\hline Average & -7.7 & -52.8 & \\
\hline Standard deviation & 0.1 & 0.7 & \\
\hline
\end{tabular}

Table 5. Isotopic results for two replicates of a recent sample from Milandre cave (Switzerland) and for the corresponding drip water. $\delta D$ values of speleothem and the modern drip water are coherent and really close, whereas $\delta^{18} \mathrm{O}$ seems to be slightly fractionated.

\begin{tabular}{lrrc}
\hline Sample & $\begin{array}{r}\delta^{18} \mathrm{O} \\
(\% \circ)\end{array}$ & $\begin{array}{r}\delta D \\
(\% \circ)\end{array}$ & $\begin{array}{r}\text { Released water } \\
(\mu \mathrm{L})\end{array}$ \\
\hline Milandre recent speleothem 2 & -7.7 & -63.0 & 0.62 \\
Milandre recent speleothem 3 & -8.1 & -61.8 & 0.67 \\
Average & -7.9 & -62.4 & \\
Standard deviation & 0.3 & 0.9 & \\
Drip water & & & \\
Average & -8.9 & -62.0 & \\
Standard deviation & 0.2 & 0.8 & \\
\hline
\end{tabular}

The sample throughput could be increased by placing two or more copper tubes in parallel to optimise the stabilisation time between speleothem crushing, or the measurement protocol could also be shortened, leading to a substantial gain in time and allowing the crushing of more than two samples per day. 
Acknowledgements. We warmly thank Kim Cobb, Jess Adkins and Nele Meckler for letting us measure one of their stalagmites. We would also like to thank Yves Krüger for his active involvement in sample preparation and for making the fluid inclusions photos available, and Peter Nyfeler for his helpful assistance and involvement in line maintenance. This study is part of "STALCLIM" and "STALCLIM II", Sinergia projects financed through the Swiss National Science Foundation (grant no. CRSI22-132646/1).

Edited by: V. Masson-Delmotte

\section{References}

Aemisegger, F., Sturm, P., Graf, P., Sodemann, H., Pfahl, S., Knohl, A., and Wernli, H.: Measuring variations of $\delta_{18} \mathrm{O}$ and $\delta_{2} \mathrm{H}$ in atmospheric water vapour using two commercial laserbased spectrometers: an instrument characterisation study, Atmos. Meas. Tech., 5, 1491-1511, doi:10.5194/amt-5-1491-2012, 2012.

Arienzo, M. M., Swart, P. K., and Vonhof, H. B.: Measurement of $\delta^{18} \mathrm{O}$ and $\delta_{2} \mathrm{H}$ values of fluid inclusion water in speleothems using cavity ring-down spectroscopy compared with isotope ratio mass spectrometry, Rapid Commun. Mass Sp., 27, 2616-2624, doi:10.1002/rcm.6723, 2013.

Badertscher, S., Fleitmann, D., Cheng, H., Edwards, R. L., Gokturk, O. M., Zumbuhl, A., Leuenberger, M., and Tuysuz, O.: Pleistocene water intrusions from the Mediterranean and Caspian seas into the Black Sea, Nat. Geosci., 4, 236-239, 2011.

Baker, A. and Bradley, C.: Modern stalagmite $\delta^{18} \mathrm{O}$ : instrumental calibration and forward modelling, Global Planet. Change, 71, 201-206, doi:10.1016/j.gloplacha.2009.05.002, 2010.

Brand, W. A., Geilmann, H., Crosson, E. R., and Rella, C. W.: Cavity ring-down spectroscopy versus high-temperature conversion isotope ratio mass spectrometry; a case study on delta H-2 and delta O-18 of pure water samples and alcohol/water mixtures, Rapid Commun. Mass Sp., 23, 1879-1884, doi:10.1002/Rcm.4083, 2009.

Cheng, H., Edwards, R. L., Broecker, W. S., Denton, G. H., Kong, X. G., Wang, Y. J., Zhang, R., and Wang, X. F.: Ice age terminations, Science, 326, 248-252, doi:10.1126/science.1177840, 2009.

Crosson, E. R.: A cavity ring-down analyzer for measuring atmospheric levels of methane, carbon dioxide, and water vapor, Appl. Phys. B-Lasers, O, 92, 403-408, doi:10.1007/s00340-008-3135y, 2008.

Daeron, M., Guo, W., Eiler, J., Genty, D., Blamart, D., Boch, R., Drysdale, R., Maire, R., Wainer, K., and Zanchetta, G.: (CO)$\mathrm{C}-13-\mathrm{O}-18$ clumping in speleothems: Observations from natural caves and precipitation experiments, Geochim. Cosmochim. Ac., 75, 3303-3317, doi:10.1016/j.gca.2010.10.032, 2011.

Dennis, P. F., Rowe, P. J., and Atkinson, T. C.: The recovery and isotopic measurement of water from fluid inclusions in speleothems, Geochim. Cosmochim. Acta, 65, 871-884, doi:10.1016/S00167037(00)00576-7, 2001

Dennis, P. F., Rowe, P. J., and Atkinson, T. C.: The stable isotope composition of palaeoprecipitation and palaeogroundwaters from speleothem fluid inclusions, International Symposium on Isotope Techniques in the Study of Past and Current Environ- mental Changes in the Hydrosphere and the Atmosphere, International Atomic Energy Agency Report IAEA-SM-349/44, Vienna, Austria, 1997.

Dublyansky, Y. V. and Spötl, C.: Hydrogen and oxygen isotopes of water from inclusions in minerals: design of a new crushing system and on-line continuous-flow isotope ratio mass spectrometric analysis, Rapid Commun. Mass Sp., 23, 2605-2613, doi:10.1002/Rcm.4155, 2009.

Fairchild, I. J., Smith, C. L., Baker, A., Fuller, L., Spötl, C., Mattey, D., McDermott, F., and E. I. M. F.: Modification and preservation of environmental signals in speleothems, Earth-Sci. Rev., 75, 105-153, doi:10.1016/j.earscirev.2005.08.003, 2006.

Fleitmann, D., Burns, S. J., Neff, U., Mangini, A., and Matter, A.: Changing moisture sources over the last 330,000 years in Northern Oman from fluid-inclusion evidence in speleothems, Quaternary Res., 60, 223-232, doi:10.1016/S0033-5894(03)000863, 2003 .

Gehre, M., Geilmann, H., Richter, J., Werner, R. A., and Brand, W. A.: Continuous flow $\mathrm{H}-2 / \mathrm{H}-1$ and and(18)O/O-16 analysis of water samples with dual inlet precision, Rapid Commun. Mass Sp., 18, 2650-2660, doi:10.1002/Rcm.1672, 2004.

Gupta, P., Noone, D., Galewsky, J., Sweeney, C., and Vaughn, B. H.: Demonstration of high-precision continuous measurements of water vapor isotopologues in laboratory and remote field deployments using wavelength-scanned cavity ring-down spectroscopy (WS-CRDS) technology, Rapid Commun. Mass. Sp., 23, 2534 2542, doi:10.1002/Rcm.4100, 2009.

Harmon, R. S., Schwarcz, H. P., and Ford, D. C.: Stable isotope geochemistry of speleothems and cave waters from flint ridgemammoth cave system, Kentucky - implications for terrestrial climate change during period 230,000 to 100,000 years BP, J. Geol., 86, 373-384, 1978.

Harmon, R. S., Schwarcz, H. P., and Oneil, J. R.: D-H ratios in speleothem fluid inclusions - guide to variations in the isotopic composition of meteoric precipitation, Earth Planet. Sc. Lett., 42, 254-266, doi:10.1016/0012-821x(79)90033-5, 1979.

Hodell, D. A., Turchyn, A. V., Wiseman, C. J., Escobar, J., Curtis, J. H., Brenner, M., Gilli, A., Mueller, A. D., Anselmetti, F., Ariztegui, D., and Brown, E. T.: Late Glacial temperature and precipitation changes in the lowland Neotropics by tandem measurement of delta O-18 in biogenic carbonate and gypsum hydration water, Geochim. Cosmochim. Ac., 77, 352-368, doi:10.1016/j.gca.2011.11.026, 2012.

Huber, C. and Leuenberger, M.: Fast high-precision on-line determination of hydrogen isotope ratios of water or ice by continuous-flow isotope ratio mass spectrometry, Rapid Commun. Mass Sp., 17, 1319-1325, doi:10.1002/Rcm.1055, 2003.

Iannone, R. Q., Romanini, D., Kassi, S., Meijer, H. A. J., and Kerstel, E. R. T.: A microdrop generator for the calibration of a water vapor isotope ratio spectrometer, J. Atmos. Ocean. Tech., 26, 1275-1288, doi:10.1175/2008jtecha1218.1, 2009.

Koehler, G. and Wassenaar, L. I.: Determination of the Hydrogen Isotopic Compositions of Organic Materials and Hydrous Minerals Using Thermal Combustion Laser Spectroscopy, Anal. Chem., 84, 3640-3645, doi:10.1021/Ac3000489, 2012.

Lachniet, M. S.: Climatic and environmental controls on speleothem oxygen-isotope values, Quaternary Sci. Rev., 28, 412-432, doi:10.1016/j.quascirev.2008.10.021, 2009. 
Leuenberger, M. and Huber, C.: On-line determination of oxygen isotope ratios of water or ice by mass spectrometry, Anal. Chem., 74, 4611-4617, doi:10.1021/Ac0203589, 2002.

Matthews, A., Ayalon, A., and Bar-Matthews, M.: D/H ratios of fluid inclusions of Soreq cave (Israel) speleothems as a guide to the Eastern Mediterranean Meteoric Line relationships in the last $120 \mathrm{ky}$, Chem. Geol., 166, 183-191, doi:10.1016/S00092541(99)00192-8, 2000.

McGarry, S., Bar-Matthews, M., Matthews, A., Vaks, A., Schilman, B., and Ayalon, A.: Constraints on hydrological and paleotemperature variations in the Eastern Mediterranean region in the last $140 \mathrm{ka}$ given by the delta D values of speleothem fluid inclusions, Quaternary Sci. Rev., 23, 919-934, doi:10.1016/j.quascirev.2003.06.020, 2004.

Meckler, A. N., Clarkson, M. O., Cobb, K. M., Sodemann, H., and Adkins, J. F.: Interglacial hydroclimate in the tropical west Pacific through the late pleistocene, Science, 336, 1301-1304, doi:10.1126/science.1218340, 2012.

Mickler, P. J., Stern, L. A., and Banner, J. L.: Large kinetic isotope effects in modern speleothems, Geol. Soc. Am. Bull., 118, 6581, doi:10.1130/B25698.1, 2006.

Moerman, J. W., Cobb, K. M., Adkins, J. F., Sodemann, H., Clark, B., and Tuen, A. A.: Diurnal to interannual rainfall delta O-18 variations in northern Borneo driven by regional hydrology, Earth Planet Sc. Lett., 369, 108-119, doi:10.1016/j.epsl.2013.03.014, 2013.

Morrison, J., Brockwell, T., Merren, T., Fourel, F., and Phillips, A. M.: On-Line High-Precision Stable Hydrogen Isotopic Analyses on Nanoliter Water Samples, Anal. Chem., 73, 3570-3575, doi:10.1021/ac001447t, 2001.

Scheidegger, Y., Baur, H., Brennwald, M. S., Fleitmann, D., Wieler, R., and Kipfer, R.: Accurate analysis of noble gas concentrations in small water samples and its application to fluid inclusions in stalagmites, Chem. Geol., 272, 31-39, doi:10.1016/j.chemgeo.2010.01.010, 2010.

Schwarcz, H. P., Harmon, R. S., Thompson, P., and Ford, D. C.: Stable isotope studies of fluid inclusions in speleothems and their paleoclimatic significance, Geochim. Cosmochim. Acta, 40, 657-665, doi:10.1016/0016-7037(76)90111-3, 1976.
Sharp, Z. D., Atudorei, V., and Durakiewicz, T.: Arapid method for determination of hydrogen and oxygen isotope ratios from water and hydrous minerals, Chem. Geol., 178, 197-210, doi:10.1016/S0009-2541(01)00262-5, 2001.

Smalley, P. C., Stijfhoorn, D. E., Raheim, A., Johansen, H., and Dickson, J. A. D.: The laser microprobe and its application to the study of $\mathrm{C}$ and $\mathrm{O}$ isotopes in calcite and aragonite, Sediment. Geol., 65, 211-221, doi:10.1016/0037-0738(89)90023-7, 1989.

Sturm, P. and Knohl, A.: Water vapor $\delta_{2} \mathrm{H}$ and $\delta_{18} \mathrm{O}$ measurements using off-axis integrated cavity output spectroscopy, Atmos. Meas. Tech., 3, 67-77, doi:10.5194/amt-3-67-2010, 2010.

Tremaine, D. M., Froelich, P. N., and Wang, Y.: Speleothem calcite farmed in situ: modern calibration of $\delta^{18} \mathrm{O}$ and $\delta^{13} \mathrm{C}$ paleoclimate proxies in a continuously-monitored natural cave system, Geochim. Cosmochim. Acta, 75, 4929-4950, doi:10.1016/j.gca.2011.06.005, 2011.

Verheyden, S., Genty, D., Cattani, O., and van Breukelen, M. R.: Water release patterns of heated speleothem calcite and hydrogen isotope composition of fluid inclusions, Chem. Geol., 247, 266281, doi:10.1016/j.chemgeo.2007.10.019, 2008.

Vonhof, H. B., van Breukelen, M. R., Postma, O., Rowe, P. J., Atkinson, T. C., and Kroon, D.: A continuous-flow crushing device for on-line $\delta_{2} \mathrm{H}$ analysis of fluid inclusion water in speleothems, Rapid Commun. Mass Sp., 20, 2553-2558, doi:10.1002/Rcm.2618, 2006.

Wainer, K., Genty, D., Blamart, D., Daeron, M., Bar-Matthews, M., Vonhof, H., Dublyansky, Y., Pons-Branchu, E., Thomas, L., van Calsteren, P., Quinif, Y., and Caillon, N.: Speleothem record of the last $180 \mathrm{ka}$ in Villars cave (SW France): Investigation of a large delta O-18 shift between MIS6 and MIS5, Quat. Sci. Rev., 30, 130-146, doi:10.1016/j.quascirev.2010.07.004, 2011.

Yonge, C. J.: Stable Isotope Studies of Water Extracted from Speleothems, PhD thesis, McMaster University, Hamilton, ON, Canada, 1982. 